\title{
HMGB1 and HMGB2 Expression Patterns in Human Papillary Renal Cancers
}

\author{
Takumi Takeuchi $^{{ }^{*}}$, Koichi Sakazume ${ }^{2}$, Akiko Tonooka ${ }^{2}$, Mami Hattori ${ }^{1}$, Masayoshi Zaitsu ${ }^{1}$, \\ Yuta Takeshima ${ }^{1}$, Koji Mikami ${ }^{1}$, Toshimasa Uekusa ${ }^{2}$ \\ ${ }^{1}$ Department of Urology, Kanto Rosai Hospital, Kawasaki, Japan \\ ${ }^{2}$ Department of Pathology, Kanto Rosai Hospital, Kawasaki, Japan \\ Email: *takeuchit@abelia.ocn.ne.jp
}

Received November 20, 2012; revised December 25, 2012; accepted January 6, 2013

\begin{abstract}
High mobility group box (HMGB) proteins are nuclear nonhistone chromosomal proteins that bend DNA, bind preferentially to distorted DNA structures, and promote the assembly of site-specific DNA binding proteins. Recent reports indicate that HMGB1 has a dual function, a cytokine in addition to a nuclear protein. The increased expression of HMGB1 has been reported for several different tumors. Here, we assessed HMGB1 and HMGB2 expressions in two cases of papillary renal cell carcinoma. One case with pT1a, Grade 2 showed HMGB1 expression in the nucleus and cytosol and HMGB2 expression in the nucleus, but not in the cytosol. In the other case, there were three renal tumors, one of which was clear cell renal cell carcinoma with pT1a, Grade 3 and two were papillary renal cell carcinomas, Grade 2 (5 $\mathrm{mm}$ and $2 \mathrm{~mm}$ in the diameter). Both HMGB1 and HMGB2 were expressed in the nucleus and cytosol of papillary carcinoma. In the clear cell carcinoma of this case, HMGB1 expression was stained both in the nucleus and cytosol, while HMGB2 was observed in the nucleus, but not in the cytosol. More samples need to be further investigated in order to draw conclusions concerning HMGB expressions in papillary renal cell carcinomas.
\end{abstract}

Keywords: Kidney; Papillary; Cancer; HMGB

\section{Introduction}

High mobility group box (HMGB) proteins are nuclear nonhistone chromosomal proteins that bend DNA, bind preferentially to distorted DNA structures, and promote the assembly of site-specific DNA binding proteins leading to the regulation of gene transcription [1]. HMGB1 has been regarded as a ubiquitous nuclear protein with an architectural function, although HMGB2 and HMGB3 expressions are relatively restricted. However, recent reports indicate that HMGB1 expression can be outside of the nucleus, and so it is not a housekeeping protein but has a dual function [2], a cytokine in addition to a nuclear protein. The receptor for advanced glycation end products (RAGE), Toll-like receptor-2 (TLR-2), and Toll-like receptor-4 (TLR-4) is known as a receptor of HMGB1 [3] and extracellular HMGB1 is an inflammation mediator and a danger signal [4].

On the contrary, Kusume and colleagues reported that HMGB1 produced by colon cancer cells disturbed anticancer immunity in the host by suppressing nodal dendritic cells [5]. The increased expression of HMGB1, particularly in conjunction with RAGE, has been re-

${ }^{*}$ Corresponding author. ported for several different tumors, including colon cancer [5], breast cancer [6], melanoma [7], prostate cancer $[8,9]$, and gastrointestinal stromal tumors [10], often indicating invasiveness, metastasis, and a poor prognosis $[11,12]$.

HMGB2 has not been reported to come out of the nuclus or cells differently from HMGB1. Ubiquitous expressions of HMGB1 and HMGB2 have the potential to regulate the transcriptional activity of different members of the p53 family in cell-specific and promotor-specific manners in vivo [13]. Both HMGB1 and HMGB2 are sensors of DNA damage inducing a p53-mediated DNA damage response, abrogation of which increased chemoresistance in some cancer cell lines [14].

Recently, we have examined immunohistological expressions of HMGB1 and HMGB2 in surgically resected human clear cell renal cancer specimens [15]. There, HMGB1 was expressed in the nucleus in $93.9 \%$ of clear cell renal cancers, while its expression in the cytosol was noted in $48.5 \%$. Cytosolic HMGB1 is expressed more frequently in cancers beyond the $\mathrm{pT} 1 \mathrm{~b}$ classification than in those at the pT1a classification. Higher tumor grades $(\mathrm{G} 2 \leq)$ were also significantly linked with the cytosolic expression of HMGB1. HMGB2 was expressed in the 
nucleus in $87.9 \%$ of clear cell renal cancers, while its expression in the cytosol was observed in only $15.2 \%$. Accordingly, we have concluded that HMGBlexpressed in the cytoplasm was correlated with poor pathological characteristics. In this line, we assessed HMGB1 and HMGB2 expressions in two cases of papillary renal cell carcinoma.

Kidney cancer genes known to be involved in the pathogenesis of the renal tumors are VHL (von HippelLindau), MET (hepatocyte growth factor receptor), FLCN (folliculin), TSC1/TSC2 (tuberous sclerosis genes), $\mathrm{FH}$ (fumaratehydratase), and $S D H$ (succinate dehydrogenase) [16]. Papillary renal cell carcinoma is the second most common subtype of RCC next to the clear cell subtype and activating mutations in the tyrosine kinase domain of $M E T$ have been detected in the hereditary and sporadic type 1 papillary renal cell carcinomas [16].

\section{Immunohistochemistry}

Paraffin-embedded sections of specimens of renal cancers excised by radical or partial nephrectomy were histochemically stained with anti-human mouse monoclonal HMGB1 antibody (Abcam, AB80246) or anti-human mouse monoclonal HMGB2 antibody (Abgent, AT2387a) as primary antibodies essentially following the manufacturers' instructions. Expressions of HMGB1/2 were determined by a single pathologist (A.T.).

\section{Case Presentation}

Case 1: Seventy-five year old male presented with incidentally found right renal tumor. An enhanced CT scan revealed almost non-enhanced tumor of $3 \mathrm{~cm}$ in the diameter in the dorsal portion of left kidney without metastasis. Partial nephrectomy was performed through left flank incision with clamp of the right renal artery for 20 minutes following surface cooling with ice slush. The pathology of the renal tumor was renal cell carcinoma of papillary subtype, pathological T1a, Grade 2. Staining with anti-HMGB1 and anti-HMGB2 antibodies showed HMGB1 expression in the nucleus and cytosol (Figure 1(a)) and HMGB2 expression in the nucleus, but not in the cytosol (Figure 1(b)).

Case 2: Seventy-eight year old male presented with incidentally found left renal tumor. An enhanced CT scan revealed heterogeneously enhanced tumor of $3.8 \mathrm{~cm}$ in the diameter in the middle of left kidney without metastasis. Left nephrectomy was performed through left flank incision. In the pathology, there were three renal tumors, one of which was clear cell renal cell carcinoma, Grade 3 indicated by the CT scan and the remaining two were papillary renal cell carcinomas, Grade $2(5 \mathrm{~mm}$ and 2 $\mathrm{mm}$ in the diameter). The latter tumors were located separately from the main clear cell cancer. Both HMGB1 and HMGB2 expressions in the cytosol as well as the nucleus of papillary renal cell carcinomas were observed (Figures 2(a) and (b)). In the clear cell carcinoma, HMGB1 expression was stained both in the nucleus and cytosol (Figure 3(a)), while HMGB2 was observed in the nucleus, but not in the cytosol (Figure 3(b)).

\section{Discussion}

HMGB1/2 expression in papillary renal cancer has not previously been reported. In both cases of papillary renal cell carcinoma in the present study whose pathological stage is pT1a, HMGB1 was expressed in the cytosol as well as in the nucleus. HMGB2 is expressed in the nucleus in both cases, while it is expressed in the cytosol in Case 2, but not in Case 1. Comparing with the patterns of HMGB1 expression in renal clear cell carcinoma, which

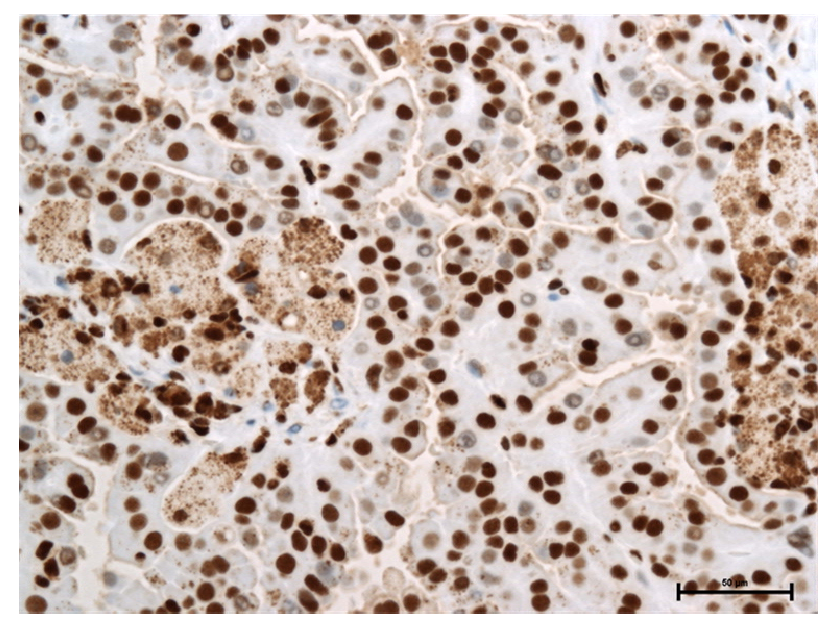

(a)

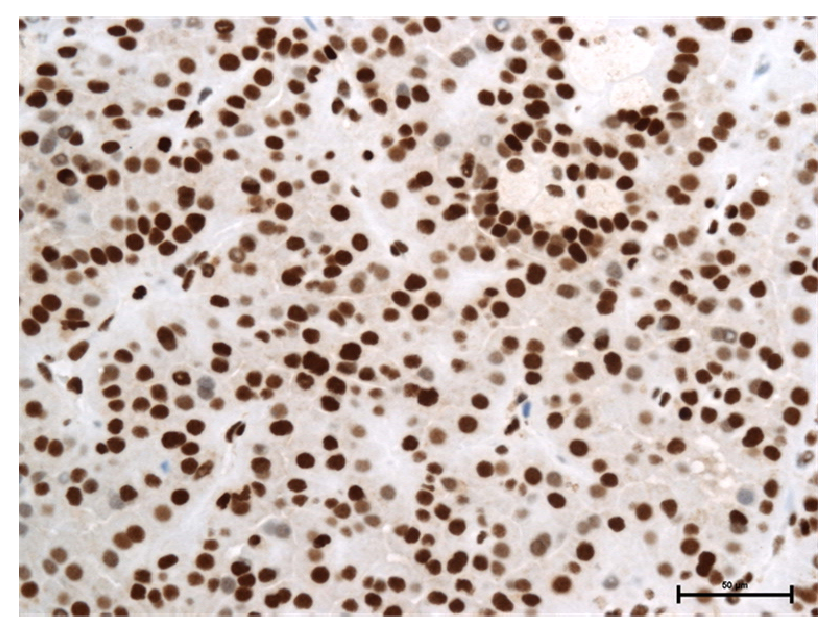

(b)

Figure 1. (a) HMGB1 staining in papillary renal cell carcinoma in Case 1. Nuclear staining+, cytoplasmic staining+, Bar $=50 \mu \mathrm{m}$; (b) HMGB2 staining in papillary renal cell carcinoma in Case 1. Nuclear staining+, cytoplasmic staining-, $\operatorname{Bar}=\mathbf{5 0} \mu \mathrm{m}$. 


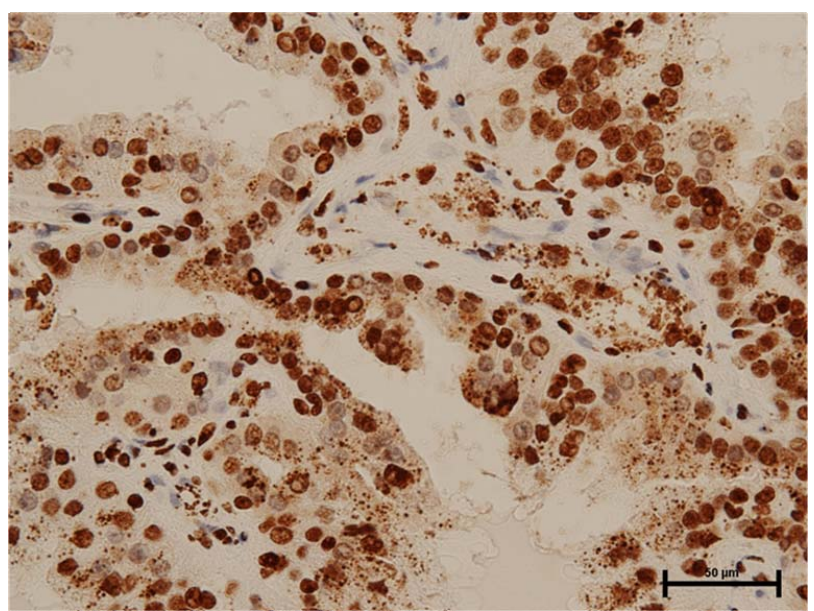

(a)

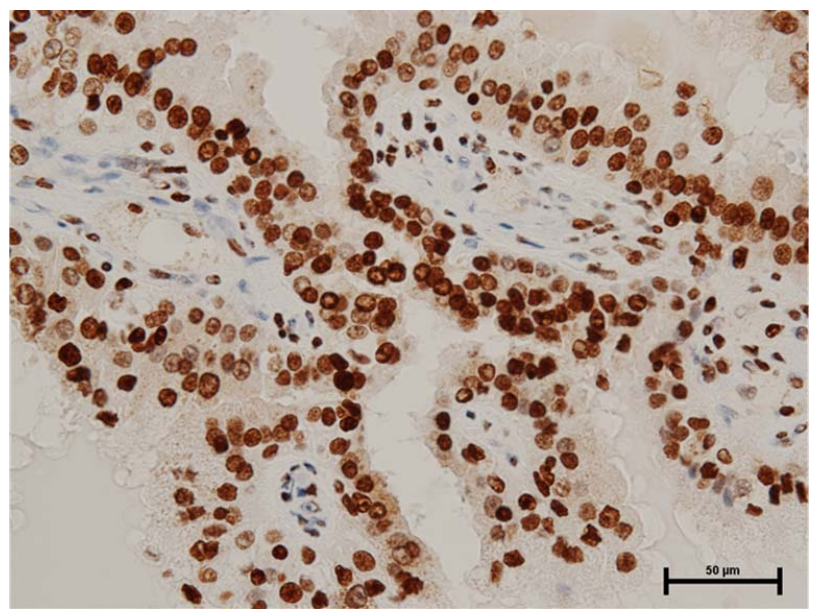

(b)

Figure 2. (a) HMGB1 staining in papillary renal cell carcinoma in Case 2. Nuclear staining+, cytoplasmic staining+, Bar $=50 \mu \mathrm{m}$; (b) HMGB2 staining in papillary renal cell carcinoma in Case 2. Nuclear staining+, cytoplasmic staining+, $B a r=50 \mu m$.

shows that HMGB1 tends not to be expressed in pT1a tumors, there may be tendency that papillary renal cell carcinomas even in the lower stage express HMGB1.

Papillary renal cell carcinomas are generally smaller and have fewer metastases at diagnosis compared with clear cell renal cell carcinomas with similar or favorable cancer specific survivals $[17,18]$. Papillary renal cell carcinomas are further differentiated into type 1 and type 2 with the latter having significant lymphovascular invasion and poorer prognosis [18]. Clearly, the two cases in the present study seem to be type 1 papillary renal cell carcinomas with their histology.

Interestingly, the pT1a, Grade 3 clear cell renal cell carcinoma in Case 2 did not express cytosolic HMGB2, while Grade 2 papillary renal cell carcinoma in the same case did express it. This may also indicate that papillary renal cell carcinomas tend to show members of the

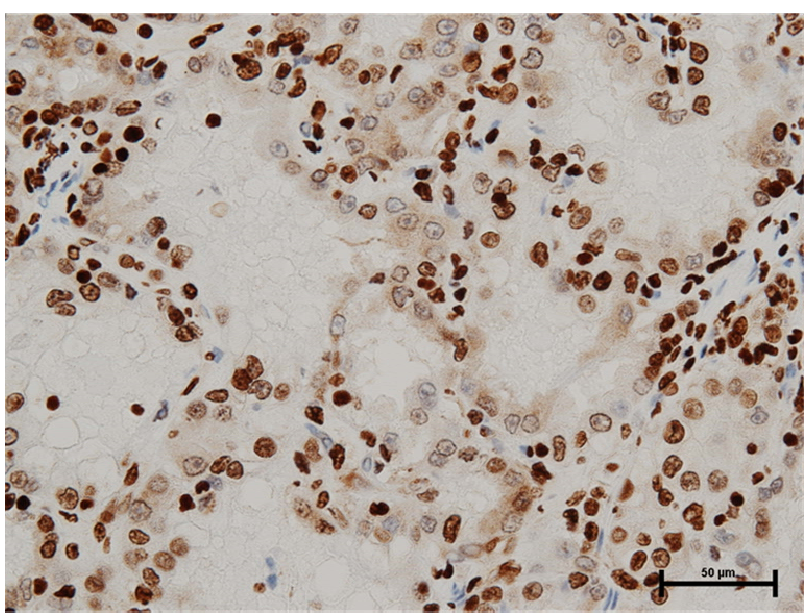

(a)

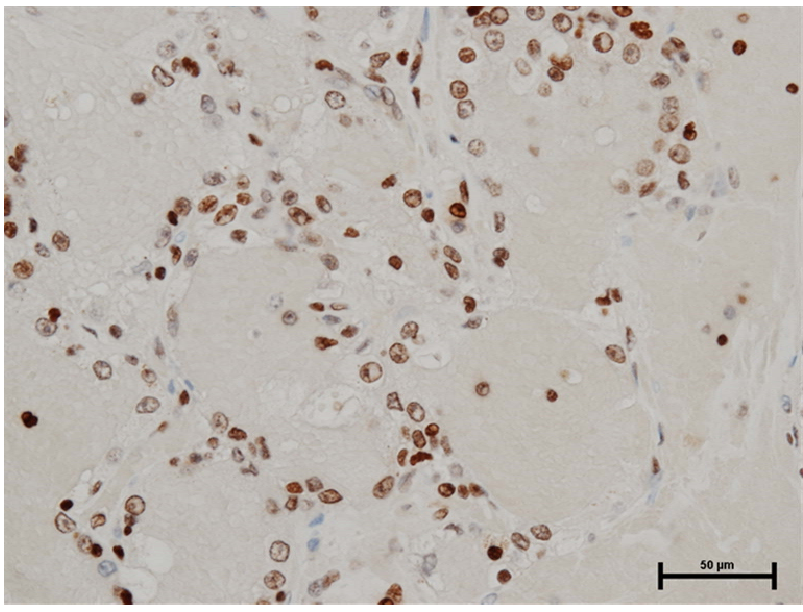

(b)

Figure 3. (a) HMGB1 staining in clear renal cell carcinoma in Case 2. Nuclear staining+, cytoplasmic staining+, Bar $=$ $50 \mu \mathrm{m}$; (b) HMGB2 staining in clear renal cell carcinoma in Case 2. Nuclear staining + , cytoplasmic staining-, Bar $=\mathbf{5 0}$ $\mu \mathrm{m}$.

HMGB family. In our previous report analyzing 33 cases, cytosolic HMGB2 expression in clear cell renal cell carcinomas could not show linkage with $\mathrm{T}$ classifications/ tumor grades, but there proved to be a weak linkage between them by increasing the sample size (unpublished data). Of course, more samples need to be further investigated in order to draw conclusions concerning HMGB expressions in papillary renal cell carcinomas.

\section{REFERENCES}

[1] J. O. Thomas and A. A. Travers, "HMG1 and 2, and Related 'Architectural' DNA-Binding Proteins," Trends in Biochemical Sciences, Vol. 26, No. 3, 2001, pp. 167-174. doi:10.1016/S0968-0004(01)01801-1

[2] S. Muller, L. Ronfani and M. E. Bianchi, "Regulated Expression and Subcellular Localization of HMGB1, a 
Chromatin Protein with a Cytokine Function," Journal of Internal Medicine, Vol. 255, No. 3, 2004, pp. 332-343. doi:10.1111/j.1365-2796.2003.01296.x

[3] A. Jaulmes, S. Thierry, B. Janvier, M. Raymondjean and V. Maréchal, "Activation of sPLA2-IIA and PGE2 Production by High Mobility Group Protein B1 in Vascular Smooth Muscle Cells Sensitized by IL-1beta," The FASEB Journal, Vol. 20, No. 10, 2006, pp.1727-1729. doi:10.1096/fj.05-5514fje

[4] H. Erlandsson-Harris and U. Andersson, "Mini-Review: The Nuclear Protein HMGB1 as a Proinflammatory Mediator," European Journal of Immunology, Vol. 34, No. 6, 2004, pp. 1503- 1512. doi:10.1002/eji.200424916

[5] A. Kusume, T. Sasahira, Y. Luo, M. Isobe, N. Nakagawa, N. Tatsumoto, K. Fujii, H. Ohmori and H. Kuniyasu, "Suppression of Dendritic Cells by HMGB1 Is Associated with Lymph Node Metastasis of Human Colon Cancer," Pathobiology, Vol. 76, No. 4, 2009, pp. 155-162. doi:10.1159/000218331

[6] M. L. Brezniceanu, K. Völp, S. Bösser, C. Solbach, P. Lichter, S. Joos and M. Zörnig, "HMGB1 Inhibits Cell Death in Yeast and Mammalian Cells and Is Abundantly Expressed in Human Breast Carcinoma," The FASEB Journal, Vol. 17, No. 10, 2003, pp. 1295-1297.

[7] I. Poser, M. Golob, R. Buettner and A. K. Bosserhoff, "Upregulation of HMG1 Leads to Melanoma Inhibitory Activity Expression in Malignant Melanoma Cells and Contributes to Their Malignancy Phenotype," Molecular and Cellular Biology, Vol. 23, No. 8, 2003, pp. 29912998. doi:10.1128/MCB.23.8.2991-2998.2003

[8] H. Kuniyasu, Y. Chihara, H. Kondo, H. Ohmori and R. Ukai, "Amphoterin Induction in Prostatic Stromal Cells by Androgen Deprivation Is Associated with Metastatic Prostate Cancer," Oncology Reports, Vol. 10, No. 6, 2003, pp. 1863-1868.

[9] M. Gnanasekar, S. Thirugnanam and K. Ramaswamy, "Short Hairpin RNA (shRNA) Constructs Targeting High Mobility Group Box-1 (HMGB1) Expression Leads to Inhibition of Prostate Cancer Cell Survival and Apoptosis," International Journal of Oncology, Vol. 34, No. 2, 2009, pp. 425-431.

[10] Y. R. Choi, H. Kim, H. J. Kang, N. G. Kim, J. J. Kim, K. S. Park, Y. K. Paik, H. O. Kim and H. Kim, "Overexpression of High Mobility Group Box 1 in Gastrointestinal Stromal Tumors with KIT Mutation," Cancer Res, Vol. 63, No. 9, 2003, pp. 2188-2193.
[11] N. Kostova, S. Zlateva, I. Ugrinova and E. Pasheva, "The Expression of HMGB1 Protein and Its Receptor RAGE in Human Malignant Tumors," Molecular and Cellular Biology, Vol. 337, No. 1-2, 2010, pp. 251-258. doi:10.1007/s11010-009-0305-0

[12] J. E. Ellerman, C. K. Brown, M. de Vera, H. J. Zeh, T. Billiar, A. Rubartelli and M. T. Lotze, "Masquerader: High Mobility Group Box-1 and Cancer," Clinical Cancer Research, Vol.13, No. 10, 2007, pp. 2836-2848. doi:10.1158/1078-0432.CCR-06-1953

[13] M. Stros, T. Ozaki, A. Bacikova, H. Kageyama and A. Nakagawara, "HMGB1 and HMGB2 Cell-Specifically Down-Regulate the p53- and p73-Dependent SequenceSpecific Transactivation from the Human Bax Gene Promoter," Journal of Biological Chemistry, Vol. 277, No. 9, 2002, pp. 7157- 7164. doi:10.1074/jbc.M110233200

[14] N. F. Krynetskaia, M. S. Phadke, S. H. Jadhav and E. Y. Krynetskiy, "Chromatin-Associated Proteins HMGB1/2 and PDIA3 Trigger Cellular Response to ChemotherapyInduced DNA Damage," Molecular Cancer Therapeutics, Vol. 8, No. 4, 2009, pp. 864-872. doi:10.1158/1535-7163.MCT-08-0695

[15] T. Takeuchi, K. Sakazume, A. Tonooka, M. Zaitsu, Y. Takeshima, K. Mikami and T. Uekusa, "Cytosolic HMGB1 Expression in Human Renal Clear Cell Cancer Indicates Higher Pathological T Classifications and Tumor Grades," Urology Journal. (In Press)

[16] W. M. Linehan, R. Srinivasan and L. S. Schmidt, "The Genetic Basis of Kidney Cancer: A Metabolic Disease," Nature Reviews Urology, Vol. 7, No. 5, 2010, pp. 277 285. doi:10.1038/nrurol.2010.47

[17] S. Steffens, M. Janssen, F. C. Roos, F. Becker, S. Schumacher, C. Seidel, G. Wegener, J. W. Thüroff, R. Hofmann, M. Stöckle, S. Siemer, M. Schrader, A. Hartmann, M. A. Kuczyk, K. Junker and A. J. Schrader, "Incidence and Long-Term Prognosis of Papillary Compared to Clear Cell Renal Cell Carcinoma-A Multicentre Study," European Journal of Cancer, Vol. 48, No. 15, 2012, pp. 2347-2352. doi:10.1016/j.ejca.2012.05.002

[18] M. Waldert, A. Haitel, M. Marberger, D. Katzenbeisser, M. Ozsoy, E. Stadler and M. Remzi, "Comparison of Type I and II Papillary Renal Cell Carcinoma (RCC) and Clear Cell RCC," BJU International, Vol. 102, No. 10, 2008, pp. 1381-1384. 